\title{
Acúmulo de nutrientes pelo meloeiro rendilhado cultivado em ambiente protegido
}

\author{
Nutrient uptake by greenhouse net melon
}

\author{
Cristiaini Kano ${ }^{1 *}$; Quirino Augusto de Camargo Carmello; \\ Silvana da Silva Cardoso ${ }^{3}$; José Antônio Frizzone ${ }^{4}$
}

\begin{abstract}
Resumo
O meloeiro rendilhado (Cucumis melo L. var reticulatus Naud.), por apresentar alto valor comercial, tem sido uma opção de plantio para os produtores de hortaliças. Com o objetivo de avaliar o acúmulo de nutrientes desse meloeiro cultivado em ambiente protegido, realizou-se este trabalho em Piracicaba, Brasil. Para obtenção do acúmulo de massa seca e dos nutrientes ao longo dos estádios fenológicos, as plantas foram coletadas no dia do transplante (muda), no desenvolvimento vegetativo, no início do florescimento, no início e no meio do período da frutificação e no período de colheita. Verificou-se que o acúmulo de nutrientes acumulados na parte aérea teve maior incremento entre o início do florescimento e o início da frutificação e o máximo acúmulo de massa seca ocorreu entre o início da frutificação e o meio do período da frutificação. A ordem decrescente dos nutrientes acumulados na parte aérea da planta foi: potássio $>$ nitrogênio $>$ cálcio $>$ magnésio $>$ enxofre $>$ fósforo $>$ ferro $>$ manganês $>$ zinco $>$ cobre $\sim$ boro.
\end{abstract}

Palavras-chave: Cucumis melo var. reticulatus Naud, demanda nutricional e fertirrigação.

\begin{abstract}
For presenting more commercial value, the net melon (Cucumis melo L. var reticulatus Naud.) has been an option of greenhouse planting for the horticulturists. This work was carried out in Piracicaba, Brazil with the aim of evaluating the nutrient uptake from this melon cultivated in greenhouse. To obtain the nutrients accumulation in the different stages of the plant development, plants were collected in the transplant day (seedling), in the vegetative stage, in the beginning of the flowering stage, in the beginning and in the middle of fruit production period and in the harvest period. It was verified that the greatest increase of nutrient uptake happened between the beginning of the flowering and the beginning of the fruit production. The greatest dry matter accumulation happened between the beginning of the fruit production and the middle of fruit production period. The decrescent order of nutrients accumulated in the above ground part of the plant was: potassium $>$ nitrogen $>$ calcium $>$ magnesium $>$ sulphur $>$ phosphorus $>$ iron $>$ manganese $>$ zinc $>$ copper $\sim$ boron.
\end{abstract}

Key words: Cucumis melo var. reticulatus Naud, nutritional demand and fertirrigation

\footnotetext{
${ }^{1}$ Pesquisadora Científica, Doutora, APTA - Agência Paulista de Tecnologia dos Agronegócios. Estrada Nelson Taufic Nacif Km 03, C. Postal 01, CEP 13910-000, Monte Alegre do Sul/SP. Fone: (19) 3899-1286, Fax: (19) 3899-1311. E-mail: criskano@hotmail. com

${ }^{2}$ Professor, Doutor, USP/ESALQ - Departamento de Solos e Nutrição de Plantas, Piracicaba/SP. E-mail: qaccarme@esalq.usp.br

${ }^{3}$ Professora, Doutora, Instituto Federal de Educação, Ciência e Tecnologia Baiano. E-mail: silvana.agronomia@hotmail.com

${ }^{4}$ Professor, Doutor, USP/ESALQ - Departamento de Engenharia Rural, Piracicaba, SP. E-mail: frizzone@esalq.usp.br

${ }^{*}$ Autor para correspondência
} 


\section{Introdução}

Para se planejar a aplicação em fertirrigação das doses dos nutrientes ao longo do ciclo de uma cultura é imprescindível o conhecimento das curvas de absorção de nutrientes (BAR-YOSEF, 1999). De forma geral, a absorção de nitrogênio, fósforo e potássio pelas culturas seguem a mesma tendência do acúmulo de material seco e a exigência destes macronutrientes pela cultura diminui à medida que o fruto amadurece. Em culturas como melão, tomate e pimenta, as quantidades exigidas de nutrientes são relativamente pequenas até o florescimento, quando, então a absorção de nutrientes se acelera, chegando ao máximo durante a frutificação (PAPADOPOULOS, 1999).

A utilização de curvas de acúmulo de nutrientes para as diversas cultivares de hortaliças, como um parâmetro para a recomendação da adubação, mostra-se como uma boa indicação da necessidade de nutrientes em cada etapa de desenvolvimento da planta; contudo, essas informações são ainda bastante limitadas (VILLAS BÔAS et al., 2001).

As informações a respeito das exigências minerais do meloeiro são escassas e não representam o comportamento dos híbridos utilizados atualmente. Conforme Silva et al. (2000), o nitrogênio e o potássio são os elementos extraídos em maiores quantidades pelo meloeiro, participando com mais de $80 \%$ do total de nutrientes extraídos $(38 \%$ e $45 \%$, respectivamente). A taxa de absorção de nutrientes pelo meloeiro é mais rápida após o início do florescimento, estendendo-se até a fase inicial da colheita.

Bar-Yosef (1999) comenta que para o melão 'Gália', o maior consumo de nitrogênio ocorreu entre 61 e 70 dias após a semeadura, enquanto que para fósforo e potássio ocorreu no período entre 71 e 80 dias após a semeadura.

Tyler e Lorenz (1964) verificaram que o período de crescimento mais rápido do melão 'Cantaloupe' iniciou-se entre 70 e 80 dias após a emergência da planta e que a absorção de nutrientes teve o mesmo comportamento que a produção de material seco. A absorção de nitrogênio e potássio foi quatro vezes maior do que a de fósforo e cálcio, e o dobro da absorção de magnésio. Tanto a produção de material seco como a absorção de nutrientes foi mais rápida no período entre o florescimento e a época de colheita. Resultado semelhante foi obtido por Maruyama, Braz e Cecílio Filho (2000), que obtiveram maior produção de material seco por planta na floração e na colheita para o híbrido Bônus $n^{\circ} 2$, cultivado em ambiente protegido.

Belfort (1985), em trabalho de campo, verificou que o melão 'Valenciano Amarelo' acumulou, em mg planta $^{-1}$, as seguintes quantidades: nitrogênio $(23,08)$, fósforo $(3,46)$, potássio $(28,90)$, cálcio $(12,74)$, magnésio $(5,55)$ e enxofre $(1,59)$, aos 75 dias após a emergência (colheita) e a produção de material seco foi de 905,9 $\mathrm{g}$ distribuída entre caule e ramos $(19,38 \%)$, folhas $(30,32 \%)$ e flores e frutos $(50,30 \%)$.

Hernández, Bustos e Zamudio (1995), em estudo com o melão híbrido Early Dew tutorado em ambiente protegido, verificaram que o cálcio foi o nutriente encontrado em maior quantidade na composição foliar $\left(51,5 \mathrm{~g} \mathrm{~kg}^{-1}\right)$, seguido por nitrogênio $\left(46,9 \mathrm{~g} \mathrm{~kg}^{-1}\right)$, potássio $\left(35,0 \mathrm{~g} \mathrm{~kg}^{-1}\right)$, fósforo $\left(4,6 \mathrm{~g} \mathrm{~kg}^{-1}\right)$ e magnésio $\left(3,7 \mathrm{~g} \mathrm{~kg}^{-1}\right)$, aos 80 dias após o transplante.

Rincón Sánchez et al. (1998) verificaram que as concentrações de nutrientes no tecido da planta mudaram durante o desenvolvimento do meloeiro cv. Toledo cultivado em ambiente protegido. $\mathrm{Na}$ colheita, as quantidades de nutrientes extraídas em g planta ${ }^{-1}$ foram de: nitrogênio $(40,48)$, fósforo $(6,8)$, potássio $(82,6)$, cálcio $(32,6)$ e magnésio $(16,6)$. No fruto, as maiores quantidades acumuladas foram de nitrogênio, fósforo e potássio e nas folhas, de cálcio e magnésio.

Bernadac et al. (1996), em estudo sobre a acumulação de cálcio nos frutos de melão (Cucumis melo var Maestro), verificaram que $80 \%$ do cálcio foi absorvido durante a primeira metade 
do desenvolvimento dos frutos. Por outro lado, Alarcón et al. (1999) verificaram que a demanda pelo cálcio aumentou consideravelmente durante o período de crescimento vegetativo intenso do melão cv. Revigal, em ambiente protegido.

$\mathrm{O}$ número de informações deficiente relativa às exigências nutricionais do meloeiro, em especial do meloeiro rendilhado, bem como a variabilidade das respostas das cultivares, quanto à extração de macronutrientes e micronutrientes, ressalta a importância do estudo de extração de nutrientes por este híbrido, que tem destaque nas condições brasileiras.

O objetivo deste trabalho foi determinar a curva de acúmulo de nutrientes pelo meloeiro rendilhado cultivado em ambiente protegido e a ordem de importância da absorção dos diferentes nutrientes.

\section{Material e Métodos}

Esse trabalho foi conduzido na estufa da área experimental do Departamento de Engenharia Rural, pertencente à Universidade de São Paulo/ Escola Superior de Agricultura "Luiz de Queiroz" (USP/ESALQ) em Piracicaba/SP, localizada a latitude sul de $22^{\circ} 42^{\prime} 30^{\prime \prime}$, longitude oeste de $47^{\circ}$ $38^{\prime} 00^{\prime \prime}$ e altitude de $580 \mathrm{~m}$.

Pelos dados climáticos obtidos durante o cultivo do meloeiro rendilhado percebeu-se que as temperaturas encontradas estavam no intervalo considerado ideal para o desenvolvimento dessa cultura (próximo da temperatura entre 25 e $32^{\circ} \mathrm{C}$ ), segundo Sousa et al. (1999), pois durante todo o ciclo da cultura, a média da temperatura mínima, máxima e média foi de 17,$1 ; 31,2$ e $23,1{ }^{\circ} \mathrm{C}$, com uma média da umidade relativa do ar de $74 \%$.

A estufa em arco apresentava as dimensões de $17,5 \mathrm{~m}$ de comprimento, largura de $7 \mathrm{~m}$ e pédireito de $3 \mathrm{~m}$. Sobre cada arco havia duas janelas para liberar o ar quente que se acumulava no alto da estufa. O teto foi coberto com filme de polietileno transparente com $150 \mu$ de espessura. Os dados de temperatura e de umidade relativa do ar foram obtidos durante o cultivo do meloeiro rendilhado através de termohigrógrafos portáteis instalados dentro da estufa.

O solo utilizado no experimento foi Latossolo Vermelho Amarelo Distrófico típico (EMBRAPA, 1999). As análises químicas do solo indicaram os seguintes resultados: $\mathrm{pH}\left(\mathrm{CaCl}_{2}\right)=4,6 ; \mathrm{P}_{\text {resina }}=4,0$ $\mathrm{mg} \mathrm{dm}{ }^{-3}$; matéria orgânica $=13,8 \mathrm{~g} \mathrm{dm}^{-3} ; \mathrm{V} \%=$ $30 \%$ e os valores de $\mathrm{H}+\mathrm{Al}$; $\mathrm{K}$; $\mathrm{Ca}$; $\mathrm{Mg}$; $\mathrm{SB}$ e CTC expressos em mmol $_{\mathrm{c}} \mathrm{dm}^{-3}$ respectivamente de: 27,8; 0,$9 ; 7,5 ; 3,3 ; 11,9$ e 39,7 . A análise física do solo indicou 152,3; 86,7 e $761 \mathrm{~g} \mathrm{~kg}^{-1}$ de argila, silte e areia, respectivamente.

Com base na análise química do solo, procedeuse a correção da acidez do solo, 60 dias antes do plantio, mediante a incorporação nos canteiros de $2,96 \mathrm{t} \mathrm{ha}^{-1}$ de calcário dolomítico $\left(390 \mathrm{~g} \mathrm{~kg}^{-1} \mathrm{de}\right.$ $\mathrm{CaO}, 130 \mathrm{~g} \mathrm{~kg}^{-1}$ de $\mathrm{MgO}$ e PRNT de 67\%), visando elevar-se a saturação por bases a $80 \%$ e o teor de magnésio a $9 \mathrm{mmol}_{\mathrm{c}} \mathrm{dm}^{-3}$ (RAIJ et al., 1996).

Decorridos 30 dias da calagem e 30 dias antes do transplante, foi feita a adubação de plantio, aplicando-se uma dose de $240 \mathrm{~kg} \mathrm{ha}^{-1}$ de $\mathrm{P}_{2} \mathrm{O}_{5}$ na forma de termofosfato Yoorin master $(17,5 \%$ de $\mathrm{P}_{2} \mathrm{O}_{5}, 0,10 \%$ de $\mathrm{B}$ e $0,55 \%$ de $\left.\mathrm{Zn}\right)$ e $30 \mathrm{t} \mathrm{ha}^{-1}$ de esterco bovino curtido (RAIJ et al., 1996).

As mudas de meloeiro rendilhado (Cucumis melo L. var reticulatus Naud.) híbrido Bônus $\mathrm{n}^{\circ}$ 2 foram preparadas em bandejas de poliestireno expandido com 128 células preenchidas com substrato comercial, colocando-se uma semente por célula, sendo posteriormente transplantadas no dia 04 de setembro de 2001 (19 dias após a semeadura), utilizando-se espaçamento de 0,30 m x 1,10 m.

Em cada canteiro, instalaram-se mourões de madeira com três fios de arame liso $\mathrm{n}^{\mathrm{o}} \mathbf{1 2}$, esticados paralelos na horizontal a 0,$7 ; 1,5$ e $2,0 \mathrm{~m}$ de altura, onde as plantas foram conduzidas com uma haste e tutoradas na vertical. A desbrota foi feita até o $11^{\circ}$ nó do caule, cerca de $0,7 \mathrm{~m}$ do colo da planta, deixando-se os demais brotos laterais com três 
folhas até a planta atingir o último fio de arame, quando foi feita a poda apical.

Como o cultivo foi conduzido em ambiente fechado, procedeu-se a polinização manual (BRANDÃO FILHO; VASCONCELLOS, 1998), durante 15 dias consecutivos a partir do surgimento das primeiras flores femininas (aos 40 dias após o transplante (DAT)).

O controle fitossanitário foi feito com base nas recomendações técnicas (SOUSA et al., 1999; SILVA et al., 2000), por meio das aplicações preventivas e de controle, com defensivos químicos e com produto natural (óleo de Nim), a cada sete dias em média e sempre que necessário. As plantas daninhas foram controladas aos 30 DAT por meio de capina manual.

Cada canteiro foi servido por uma linha para irrigação e outra para fertirrigação. O sistema de irrigação utilizado foi por gotejamento e a freqüência de irrigação foi de dois dias com a quantidade de água aplicada calculada em função do potencial mátrico da água no solo no momento da irrigação. Essa quantidade de água foi determinada indiretamente com base na curva de retenção de água no solo e nas leituras diárias médias de tensão de água, realizadas com leitor digital em quatro baterias com quatro tensiômetros, instalados na estufa a 0,$10 ; 0,20$; 0,30 e $0,40 \mathrm{~m}$ de profundidade. Procurou-se manter a tensão de água no solo entre 10 e 15 kPa (CARRIJO; MAROUELLI; SILVA, 1999).

O sistema de fertirrigação operou de forma independente do sistema de irrigação. A cada fertirrigação, aplicava-se apenas água até que as linhas ficassem pressurizadas e em seguida injetava-se, com uma bomba centrífuga $(0,5 \mathrm{CV})$, um volume conhecido de calda fertilizante, a partir de um reservatório específico, de onde a calda era succionada e distribuída para as linhas de gotejadores. Após a injeção da calda fertilizante, aplicava-se mais um volume conhecido de água, para a lavagem do sistema e expulsão do restante da calda fertilizante nas linhas.
A aplicação de fertilizantes foi iniciada no $4^{\circ}$ DAT, com freqüência de quatro dias, totalizando 19 fertirrigações realizadas até o $76^{\circ}$ DAT. Durante o ciclo da cultura foram aplicados $200 \mathrm{~kg} \mathrm{ha}^{-1}$ de $\mathrm{N}$ em cobertura, na forma de nitrato de potássio e nitrato de amônio até $64^{\circ}$ DAT. A quantidade total de potássio aplicada no ciclo foi de $300 \mathrm{~kg} \mathrm{ha}^{-1}$ de $\mathrm{K}_{2} \mathrm{O}$ na forma de nitrato de potássio até $64^{\circ}$ DAT e na forma de sulfato de potássio entre os $64^{\circ}$ até $76^{\circ}$ DAT.

Para avaliar o acúmulo de nutrientes pelo meloeiro rendilhado, foram definidas seis épocas de coleta de material vegetativo: a) transplante (0 DAT); b) desenvolvimento vegetativo (15 DAT); c) início do florescimento (20 DAT); d) início da frutificação (52 DAT); e) meio do período da frutificação (72 DAT) e f) início da colheita dos frutos (97 DAT).

Cada parcela foi constituída por 13 plantas. Para obtenção dos resultados de massa de material seco e, posteriormente dos acúmulos dos nutrientes, nas épocas 0 e 15 DAT analisou-se a parte aérea da planta inteira. A partir da época 20 DAT a planta foi subdividida em folhas, caule e ramos e a partir da época 52 DAT, as flores e frutos também foram subdivididos.

Depois de secas, as amostras foram pesadas em balança analítica, obtendo-se a massa de material seco de caule e ramos, folhas, flores e de cada fruto. A separação das plantas por órgãos foi feita para poder obter os teores dos nutrientes nos diferentes órgãos.

As amostras foram levadas para o Laboratório de Nutrição Mineral de Plantas da USP/ESALQ, sendo devidamente lavadas, secas, moídas e analisadas. As análises químicas para a determinação dos teores de nutrientes presentes em cada órgão das plantas foram feitas nos extratos obtidos pela digestão sulfúrica (nitrogênio), nítrico-perclórica (fósforo, potássio, cálcio, magnésio, enxofre, cobre, ferro, manganês e zinco) e por via seca (boro) (SARRUGE; HAAG, 1974). O nitrogênio foi quantificado pelo 
método semi-micro Kjeldahl, fósforo e boro por colorimetria, potássio por fotometria de chama e cálcio, magnésio, enxofre, cobre, manganês, zinco e ferro por espectrofotometria de absorção atômica (SARRUGE; HAAG, 1974).

A partir das análises químicas foram obtidos os teores de nitrogênio, fósforo, potássio, cálcio, magnésio e enxofre em $\mathrm{g} \mathrm{kg}^{-1}$ e os teores de boro, cobre, ferro, manganês e zinco em $\mathrm{mg} \mathrm{kg} \mathrm{kg}^{-1}$. A quantidade dos nutrientes acumulados em cada parte da planta foi obtida pela multiplicação do teor de cada nutriente pela massa seca do referente órgão (amostra), obtendo-se os resultados dos macronutrientes avaliados em mg planta $^{-1}$ e dos micronutrientes em $\mu$ g planta $^{-1}$.

Todos os resultados foram obtidos a partir de quatro repetições. Os acúmulos dos nutrientes e da massa seca ao longo das épocas avaliadas foram submetidos à análise de variância pelo teste $\mathrm{F}$ e, quando significativos, foram ajustadas equações não lineares.

\section{Resultados e Discussão}

O início do florescimento (20 DAT) foi caracterizado quando ocorreu o aparecimento da primeira flor aberta na haste principal (caule).

Na Tabela 1 encontram-se os dados médios das características dos frutos das plantas coletadas, no período de frutificação (52 a 97 DAT). Aos 16 dias após a polinização das flores localizadas no $11^{\circ}$ nó (56 DAT) observou-se o início do rendilhamento dos frutos, sendo a colheita desses frutos realizada cerca de 40 dias após o início do rendilhamento, ou seja, 97 DAT.

Tabela 1. Resultados médios das características dos frutos das plantas coletadas no período de frutificação.

\begin{tabular}{cccccc}
\hline DAT & Rendilhamento & $\begin{array}{c}\text { MVF } \\
\left(\text { g fruto }^{-1}\right)\end{array}$ & $\begin{array}{c}\text { Comp } \\
(\mathrm{mm})\end{array}$ & $\begin{array}{c}\text { Diam } \\
(\mathrm{mm})\end{array}$ & Relação Diam/Comp \\
\hline 52 & ausente & 37,92 & 47,47 & 29,81 & 0,61 \\
72 & início & 638,50 & 112,11 & 100,23 & 0,89 \\
97 & completo & 845,97 & 122,72 & 106,39 & 0,87 \\
\hline
\end{tabular}

DAT = dias após o transplante; MVF = massa verde do fruto; Comp = comprimento do fruto e Diam = diâmetro do fruto.

A produtividade total de frutos verificada foi de $1,8 \mathrm{~kg}$ planta $^{-1}$, ou seja, 61,6 t ha ${ }^{-1}$, semelhante à média obtida por Gualberto, Resende e Losasso (2001) com este mesmo híbrido, que foi de $60 \mathrm{tha}^{-1}$.

Para todos os nutrientes e para a massa seca acumulada na parte aérea, o melhor ajuste foi para a função de Boltzmann, que produziu uma curva sigmoidal.

Quanto aos macronutrientes, a quantidade de nitrogênio, fósforo, potássio, cálcio, magnésio e enxofre acumulada na parte aérea das plantas (caule + ramos + folhas + frutos + flores) ao longo das épocas avaliadas ajustaram-se a função de Boltzmann (curva sigmoidal) demonstrada na Tabela 2 e Figura 1A a 1F.
A curva de acúmulo indicou que a maior absorção de nitrogênio e cálcio (Figura 1A e 1D) ocorreu no período desde o início do florescimento até o início da frutificação (20 aos 52 DAT), com uma média de 90,1 e 90,6 mg dia ${ }^{-1}$ planta $^{-1}$ de nitrogênio e cálcio, respectivamente. Já para fósforo (Figura 1B) e potássio (Figura 1C), o maior acúmulo desses nutrientes ocorreu no período de início do florescimento até o meio da época de frutificação (20 a 72 DAT), com uma média de 11,3 e 125,5 mg dia $^{-1}$ planta $^{-1}$ de fósforo e potássio, respectivamente. Para magnésio e enxofre, o maior acúmulo desses nutrientes ocorreu a partir do início do florescimento até a colheita dos frutos (20 a 97 DAT), com uma média de 25,6 e 18,2 $\mathrm{mg} \mathrm{dia}^{-1}$ planta $^{-1}$ de magnésio e enxofre, respectivamente. 
Tabela 2. Parâmetros da equação não linear ajustada para a quantidade de nutrientes e de massa seca acumulada na parte aérea do meloeiro rendilhado.

\begin{tabular}{cccccc}
\hline Acúmulo $(\mathrm{y})$ & $\mathrm{A}_{1}$ & $\mathrm{~A}_{2}$ & $\mathrm{x}_{0}$ & $\mathrm{dx}$ & $\mathrm{R}^{2}$ \\
\hline $\mathrm{N}$ & $-104,31$ & 5063,1 & 47,169 & 10,220 & 0,99 \\
$\mathrm{P}$ & $-19,633$ & 712,27 & 49,305 & 11,293 & 0,99 \\
$\mathrm{~K}$ & 3,3493 & 7048,4 & 48,227 & 7,4307 & 0,99 \\
$\mathrm{Ca}$ & $-548,93$ & 5865,2 & 51,363 & 17,362 & 0,98 \\
$\mathrm{Mg}$ & $-335,10$ & 3256,1 & 76,959 & 29,904 & 0,98 \\
$\mathrm{~S}$ & $-119,16$ & 1605,0 & 57,802 & 18,271 & 0,99 \\
$\mathrm{~B}$ & $-254,76$ & 5903,0 & 47,520 & 11,819 & 0,99 \\
$\mathrm{Cu}$ & $-98,125$ & 10301 & 66,784 & 12,678 & 0,99 \\
$\mathrm{Fe}$ & $-8336,7$ & $1,2928 \mathrm{E} 5$ & 96,431 & 31,802 & 0,99 \\
$\mathrm{Mn}$ & $-7570,0$ & 90666 & 120,55 & 45,424 & 0,98 \\
$\mathrm{Zn}$ & $-816,50$ & 10954 & 45,084 & 13,381 & 0,98 \\
Massa seca (y) & $-8,4447$ & 332,05 & 62,441 & 14,368 & 0,99 \\
\hline
\end{tabular}

$\mathrm{R}^{2}=$ coeficiente de determinação.

Equação:

$$
y=\frac{A_{1}-A_{2}}{1+e^{\left(x-x_{0}\right) / d x}}+A_{2}
$$

$\left(\mu \mathrm{g}\right.$ planta $\left.^{-1}\right)$ para micronutrientes e em $\left(\mathrm{g} \mathrm{planta}^{-1}\right)$ para massa seca.

Quanto ao nitrogênio (Figura 1A), o acúmulo foi crescente até o meio do período de frutificação (72 DAT), tendendo a não se alterar a partir dessa época. A quantidade de nitrogênio acumulada ao final do ciclo (97 DAT) foi de $5064 \mathrm{mg} \mathrm{planta}^{-1}$. O meloeiro encontrava-se com $1 \%, 4 \%, 61 \%$ e $91 \%$ do total do nitrogênio acumulado (5064 mg planta ${ }^{-1}$ ), aos 15 , 20, 52 e 72 DAT, respectivamente (Figura 1A).

Quanto ao fósforo (Figura 1B), a quantidade acumulada desse nutriente ao final do ciclo (97 DAT) foi de $708 \mathrm{mg}$ planta $^{-1}$. A planta estava com $0,8 \%, 4 \%, 56 \%$ e $87 \%$ do total do fósforo acumulado (708 mg planta ${ }^{-1}$ ), aos 15, 20, 52 e 72 DAT, respectivamente.

O potássio foi o nutriente mais acumulado pelo meloeiro. Aos 97 DAT, o acúmulo foi de $7016 \mathrm{mg}$ planta $^{-1}$. A planta estava com $0,6 \%, 3 \%, 63 \%$ e $97 \%$ do total do potássio acumulado (7016 $\mathrm{mg} \mathrm{planta}^{-1}$ ), aos 15, 20, 52 e 72 DAT respectivamente (Figura $1 \mathrm{C})$.

Quanto ao cálcio, aos 97 DAT, o acúmulo foi de $5560 \mathrm{mg} \mathrm{planta}^{-1}$. A planta encontrava-se com $0,6 \%$, $2 \%, 54 \%$ e $73 \%$ do total do cálcio acumulado, aos
15, 20, 52 e 72 DAT respectivamente (Figura 1D).

$\mathrm{O}$ acúmulo de magnésio, aos 97 DAT, foi de $2059 \mathrm{mg}$ planta $^{-1}$. A planta estava com $0,6 \%, 2 \%$, $43 \%$ e $60 \%$ do total do magnésio acumulado, aos 15, 20, 52 e 72 DAT respectivamente (Figura 1E).

Quanto ao enxofre, aos 97 DAT, o acúmulo foi de $1440 \mathrm{mg}$ planta $^{-1}$. A planta encontrava-se com $0,4 \%, 2 \%, 46 \%$ e $71 \%$ da média do total do enxofre acumulado, aos 15, 20, 52 e 72 DAT respectivamente (Figura 1F).

A média da quantidade de macronutrientes acumulada na parte aérea das plantas do meloeiro rendilhado no final do ciclo, em ordem decrescente, e em mg planta ${ }^{-1}$, foi: $7016>5560>5064>2059$ $>1440>708$, de potássio $>$ cálcio $>$ nitrogênio $>$ magnésio $>$ enxofre $>$ fósforo, respectivamente.

Quanto aos micronutrientes, a quantidade de boro, cobre, ferro, manganês e zinco acumulada na parte aérea das plantas (caule + ramos + folhas + frutos + flores) ao longo das épocas avaliadas também se ajustaram à função de Boltzmann (curva sigmoidal) (Tabela 2 e Figura 2A a 2E). 

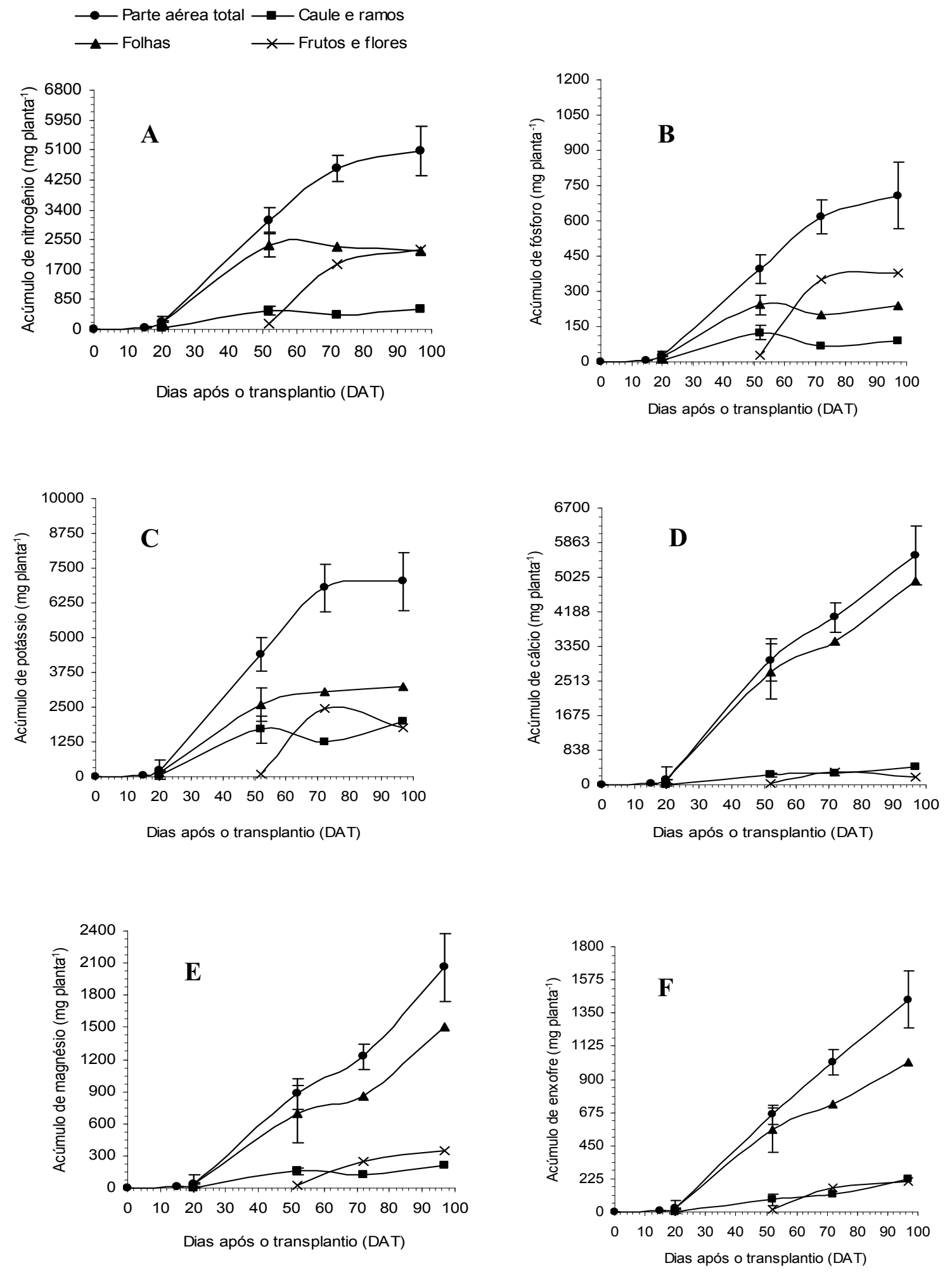

Figura 1. Curva de acúmulo de nitrogênio (A), fósforo (B), potássio (C), cálcio (D), magnésio (E) e de enxofre (F) pelo meloeiro rendilhado ao longo do ciclo. As linhas verticais indicam o erro padrão da média. 

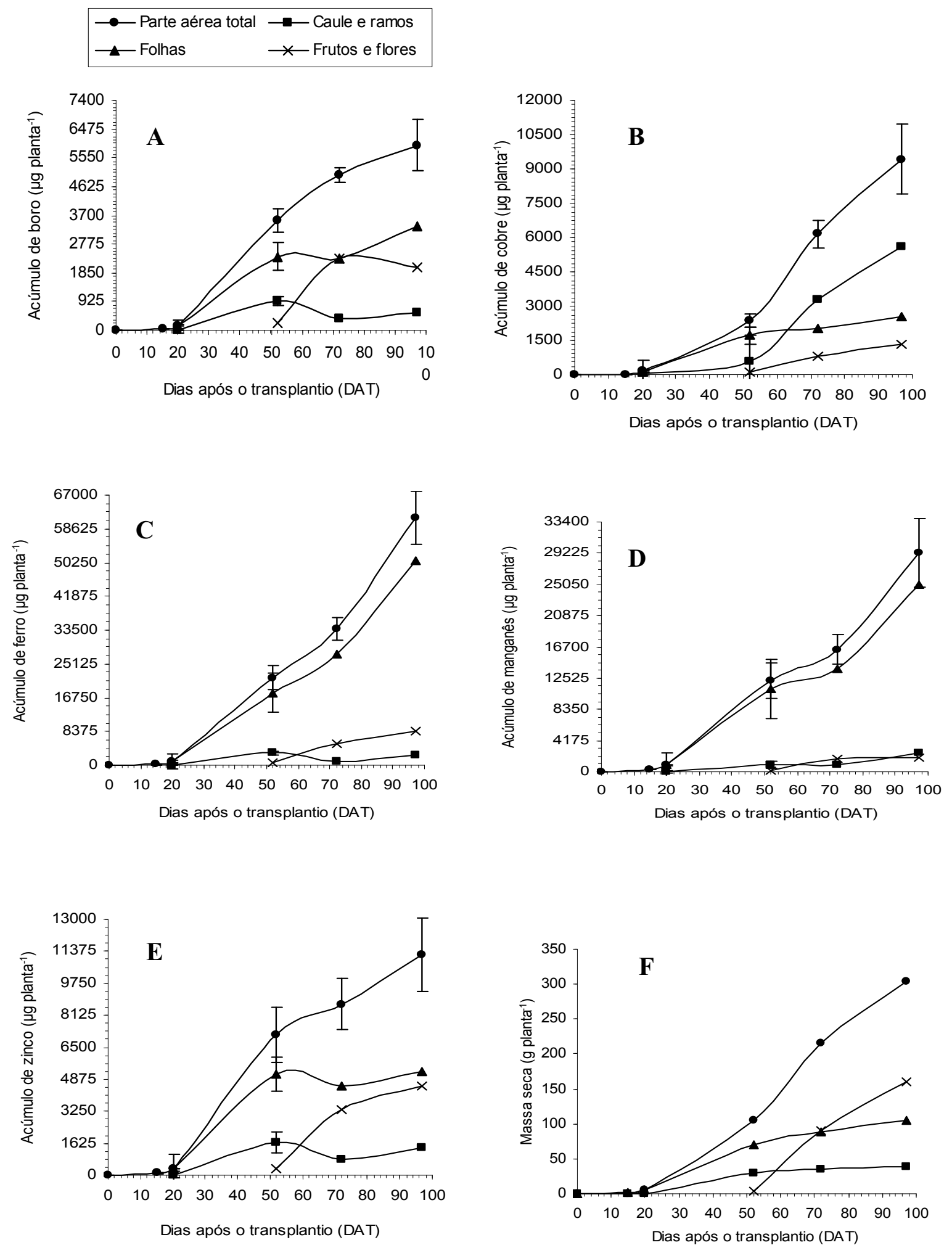

Figura 2. Curvas de acúmulo de boro (A), cobre (B), ferro (C), manganês (D), zinco (E) e de massa seca (F) pelo meloeiro rendilhado ao longo do ciclo. As linhas verticais indicam o erro padrão da média. 
A curva de acúmulo indicou que a maior quantidade de boro e zinco ocorreu no período de início do florescimento ao início da frutificação (20 aos 52 DAT), com média de 105,6 e 211,6 $\mu \mathrm{g}$ dia $^{-1}$ planta $^{-1}$ de boro e zinco, respectivamente (Figura 2A e 2E). Já para o cobre, o maior acúmulo ocorreu no período de início da frutificação ao meio do período da frutificação (52 aos 72 DAT), com média de 188,6 $\mu \mathrm{g}$ dia $^{-1}$ planta $^{-1}$ de cobre (Figura 2B). O maior acúmulo para o ferro $\left(1106,3 \mu \mathrm{g} \mathrm{dia}{ }^{-1}\right.$ planta ${ }^{-1}$ de ferro) e manganês (519 $\mu \mathrm{g} \mathrm{dia}^{-1}$ planta $^{-1}$ de manganês) ocorreu a partir do meio do período da frutificação até a colheita, entre os 72 e os 97 DAT (Figura 2C e 2D).

Quanto à quantidade de boro (Figura 2A) acumulada na parte aérea das plantas aos 97 DAT, a absorção desse nutriente foi de $5945 \mu \mathrm{g}$ planta $^{-1}$. O meloeiro estava com $0,7 \%, 3 \%, 60 \%$ e $84 \%$ do total do boro acumulado aos 15, 20, 52 e 72 DAT respectivamente.

Para o cobre (Figura 2B), a quantidade acumulada na parte aérea das plantas foi maior entre o início da frutificação e o meio do período da frutificação (52 a 72 DAT), onde o acúmulo de cobre foi de 188,6 $\mu \mathrm{g}$ planta $^{-1}$. A planta estava com $0,1 \%, 2 \%, 25 \%$ e $65 \%$ do total do cobre acumulado, aos 15, 20, 52 e 72 DAT respectivamente.

A quantidade de ferro (Figura 2C) acumulada na parte aérea das plantas aos 97 DAT foi de 61.353 $\mu \mathrm{g}$ planta $^{-1}$. A planta encontrava-se com $0,3 \%, 2 \%$, $35 \%$ e $55 \%$ da média total do ferro acumulado, aos $15,20,52$ e 72 DAT, respectivamente.

Para o manganês (Figura 2D), a maior quantidade acumulada na parte aérea das plantas foi entre o meio do período da frutificação e a colheita (72 a 97 DAT), onde o acúmulo desse nutriente na parte aérea das plantas foi de $519 \mu \mathrm{g}$ planta $^{-1}$. A planta estava com $1 \%, 3 \%, 42 \%$ e $56 \%$ do total do manganês acumulado aos 15, 20, 52 e 72 DAT, respectivamente.

A quantidade acumulada de zinco na parte aérea das plantas aos 97 DAT foi de $11.211 \mu \mathrm{g}$ planta $^{-1}$ (Figura 2E). A planta encontrava-se com 1\%, 3\%,
$64 \%$ e $77 \%$ do total do zinco acumulado aos 15,20 , 52 e 72 DAT respectivamente.

A média da quantidade de micronutrientes acumulados na parte aérea das plantas do meloeiro rendilhado no final do ciclo, em ordem decrescente e em $\mu$ g planta ${ }^{-1}$, foi: $61.353>29.306>11.211>$ $9.424>5.945$, de ferro $>$ manganês $>$ zinco $>$ cobre $>$ boro, respectivamente.

Trabalhos realizados com melão por Belfort (1985), Prata (1999), Lima (2001) e Silva Júnior et al. (2006), conduzidos em diferentes locais, cultivares e sistemas de produção, mostraram uma curva padrão de acúmulo de massa seca e de nutrientes, mais lento nos primeiros 30 dias de ciclo e com maiores demandas após o início da frutificação.

A massa seca da parte aérea das plantas ajustouse à função de Boltzmann (curva sigmoidal) demonstrada na Tabela 2. O máximo incremento do acúmulo de massa seca por planta ocorreu entre o início da frutificação e o meio do período da frutificação (52 e 72 DAT) e foi de $5,53 \mathrm{~g} \mathrm{dia}^{-}$ ${ }^{1}$ planta $^{-1}$. O acúmulo de massa seca no final do ciclo (97 DAT) foi de $304 \mathrm{~g}$ planta $^{-1}$. O meloeiro encontrava-se com $0,3 \%, 2 \%, 34 \%$ e $71 \%$ do total da massa seca acumulada (304 g planta ${ }^{-1}$ ), aos 15, 20, 52 e 72 DAT, respectivamente (Figura 2F). A partir dos 52 DAT, verificou-se tendência de estabilização do acúmulo de massa seca da parte vegetativa e elevação do acúmulo de massa seca dos frutos, demonstrando que houve translocação de carboidratos e outros compostos das folhas para os frutos (MARSCHNER, 1995).

\section{Conclusões}

O período de maior acúmulo dos nutrientes por esse híbrido de melão foi entre o início do florescimento e o início da frutificação.

A ordem decrescente dos nutrientes acumulados na parte aérea da planta foi: potássio $>$ nitrogênio $>$ cálcio $>$ magnésio $>$ enxofre $>$ fósforo $>$ ferro $>$ manganês $>$ zinco $>$ cobre $\sim$ boro. 


\section{Agradecimentos}

A CAPES pela bolsa de mestrado concedida à primeira autora e à FAPESP pelo auxílio financeiro e bolsa de doutorado à segunda autora.

\section{Referências}

ALARCÓN, A. L.; MADRID, R.; EGEA, C.; GUILLÉN, I. Calcium deficiency provoked by the application of different forms and concentrations of $\mathrm{Ca}^{2+}$ to soilless cultivated muskmelons. Scientia Horticulturae, Amsterdam, v. 81, n. 1, p. 89-102, 1999.

BAR-YOSEF, B. Advances in fertigation. Advances in Agronomy, Delaware, v. 65, n. 2, p. 1-77, 1999.

BELFORT, C. C. Acumulação de matéria seca e recrutamento de nutrientes em melão (Cucumis melo L. cv. Valenciano Amarelo CAC) cultivado em latossolo vermelho amarelo em Presidente Wenceslau/SP. 1985. Tese (Doutorado em Agronomia) - Escola Superior de Agricultura "Luiz de Queiroz". Universidade de São Paulo, Piracicaba.

BERNADAC, A.; JEAN-BAPTISTE, I.; BERTONI, G.; MORARD, P. Changes in calcium contents during melon (Cucumis melo L.) fruit development. Scientia Horticulturae, Amsterdam, v. 66, n. 3, p. 181-189, 1996.

BRANDÃO FILHO, J. V. T.; VASCONCELLOS, M. A. S. A cultura do meloeiro. In: GOTO, R.; TIVELLI, S. W. (Ed.). Produção de hortaliças em ambiente protegido: condições subtropicais. São Paulo: Fundação Editora da UNESP, 1998. Cap. 6, p. 161-193.

CARRIJO, O. A.; MAROUELLI, W. A.; SILVA, H. R. Manejo da água na produção de hortaliças em cultivo protegido. Informe Agropecuário, Minas Gerais, v. 20, n. 200/201, p. 45-51. 1999.

EMPRESA BRASILEIRA DE PESQUISA AGROPECUÁRIA - EMBRAPA. Centro Nacional de Pesquisa de Solos (Rio de Janeiro, RJ). Sistema brasileiro de classificação de solos. Brasília: EmbrapaSPI, Embrapa-CNPS, 1999. 412 p.

GUALBERTO, R.; RESENDE, F. V.; LOSASSO, P. H. L. Produtividade e qualidade do melão rendilhado em ambiente protegido, em função do espaçamento e sistema de condução. Horticultura Brasileira, Brasília, v. 19, n. 3, p. 373-376, 2001.

HERNÁNDEZ, C.; BUSTOS, V.; ZAMUDIO, N. Fertirrigacion del melon bajo invernadero plastico. Revista Industrial y Agrícola de Tucumán, Tucumán, v. 72, n. 1/2, p. 1-4, 1995.

LIMA, A. A. de. Absorção e eficiência de utilização de nutrientes por híbridos de melão (Cucumis melo L.). 2001. Dissertação (Mestrado em Solos e Nutrição de Plantas) - Departamento de Ciências do Solo. Universidade Federal do Ceará, Fortaleza.

MARSCHNER, H. Mineral nutrition of higher plants. 2. ed. London: Academic Press, 1995. 889 p.

MARUYAMA, W. I.; BRAZ, L. T.; CECÍLIO FILHO, A. B. Condução de melão rendilhado sob cultivo protegido. Horticultura Brasileira, Brasília, v. 18, n. 3, p. 175-178, 2000.

PAPADOPOULOS, I. Tendências da fertirrigação. In: FOLEGATTI, M. V. (Coord.). Fertirrigação: citrus, flores e hortaliças. Guaíba: Agropecuária, 1999. p. 11-155.

PRATA, E. B. Acumulação de biomassa e absorção de nutrientes por híbridos de meloeiro (Cucumis melo L.). 1999. Dissertação (Mestrado em Solos e Nutrição de Plantas) - Departamento de Ciências do Solo. Universidade Federal do Ceará, Fortaleza.

RAIJ, B. V.; CANTARELlA, H.; QUAGGIO, J. A.; FURLANI, A. M. C. Recomendações de adubação e calagem para o Estado de São Paulo. 2. ed. Campinas: Instituto Agronômico \& Fundação IAC, 1996. 285 p.

RINCÓN SÁNCHEZ, L.; SÁEZ SIRONI, J.; PÉREZ CRESPO, J. A.; MADRID, R. Growth and nutrient absorption by muskmelon crop under greenhouse conditions. Acta Horticulture, Wageningen, v. 458, n. 3, p. 153-159, 1998.

SARRUGE, J. R.; HAAG, H. P. Análises químicas em plantas. Piracicaba: Esalq, 1974. 56 p.

SILVA JÚNIOR, M. J. da; MEDEIROS, J. F. de; OLIVEIRA, F. H. T. de; DUTRA, I. Acúmulo de matéria seca e absorção de nutrientes pelo meloeiro "pele-desapo". Revista Brasileira de Engenharia Agrícola e Ambiental, Campina Grande, v. 10, n. 2, p. 364-368. 2006.

SILVA, H. R.; MAROUELLI, W. A.; SILVA, W. L. C.; SILVA, R. A.; OLIVEIRA, L. A.; RODRIGUES, A. G.; SOUZA, A. F.; MAENO, P. Cultivo do meloeiro para o norte de Minas Gerais. Brasília: Embrapa Hortaliças, 2000. 22 p. (Circular Técnica, 20).

SOUSA, V. F. de; RODRIGUES, B. R. N.; ATHAYDE SOBRINHO, C.; COELHO, E. F.; VIANA, F. M. P.; SILVA, P. H. S. Cultivo do meloeiro sob fertirrigação por gotejamento no meio norte do Brasil. Teresina: Embrapa Meio-Norte, 1999. 68 p. (Circular Técnica, 21).

TYLER, K. B.; LORENZ, O. A. Nutrient absorption and growth of four muskmelon varieties. Journal of the American Society for Horticultural Science, Alexandria, v. 84, n. 1, p. 191-195, 1964.

VILLAS BÔAS, R. L.; ANTUNES, C. L.; BOARETTO, A. E.; SOUSA, V. F. de; DUENHAS, L. H. Perfil da pesquisa e emprego da fertirrigação no Brasil. In: FOLEGATTI, M. V. (Coord.). Fertirrigação: flores, frutas e hortaliças. Guaíba: Agropecuária, 2001. v. 2, Cap. 2, p. 71-103. 